\title{
NEWER TECHNOLOGIES FOR THE DELIVERY AND MANAGEMENT OF DISTANCE AND E-LEARNING
}

\author{
*Bello, Idris and Zakari, Abdulraheem \\ Department of Networking, Directorate of Information and Communications Technology, \\ Kaduna Polytechnic, Nigeria.
}

\begin{abstract}
Distance learning through e-learning courses has become the most important and commonly requested mode of learning in the higher education system over the past decade. Many aspects of our lives have been upended by COVID-19 including education. Distance education became a requirement at lightning speed, due to the pandemic and worldwide shutdown. According to the University of Kansas, at the height of the COVID-19 outbreak in early April, more than 1.5 billion students, or 91.3 percent of global enrolment, were directly affected by school closures. The question of whether or not to migrate from physical classroom is no more the priority but how quick and efficiently we can adopt distance learning. This paper evaluates the incorporation of the emerging technologies into the concepts of distance learning in terms of efficiency in the teaching and learning environment at universities, polytechnics and colleges.
\end{abstract}

Keywords: Distance learning, e-Learning, new technology, COVID-19, education. 


\subsection{Introduction}

The true meaning of the "information age" and communication are rapidly evolving. Technologies previously deemed advanced are becoming commonplace and new technologies are still being developed. In the multitude of meanings of long-distance learning, the essence of this pattern is evident (Bingham, Davis \& Moore, Emerging Technologies in Distance Learning, 2020).

The U. S. Office of Technology Assessment defines distance learning as the "linking of a teacher and students in several geographic locations via technology that allows for interaction" (in Cartwright, 1994). According to the United States Distance Learning Association, "distance learning is the application of electronic means to education in all areas: K-12, higher education, continuing education, corporate training, and military and government training, telemedicine and those devoted to the pursuit of lifelong learning" (USDLA, 1996).

Many distance learning definitions include the use of technology. However, others refer to the level of interactivity and the distance between students. Some concepts do not require technology to be used. In fact, distance learning can be as easy as postal correspondence and telephone communications in the older paradigm.

Due to the technological advances of the recent past, a great deal of excitement and hope has been generated for the use of distance learning in education. Rapid advances in computer and telecommunications capabilities have made possible the development of learning modules that include elements such as video transmission, e-mail, the Internet, and the World Wide Web (Bingham, Davis \& Moore, Emerging Technologies in Distance Learning, 2020).

These emerging technologies are making education more entertaining, exciting, and malleable at a distance, not to mention enjoyable, despite some of the initial frustrations some instructors experience with learning them (Athena Kennedy, 2015).

Students can contact instructors and classmates through email, text messaging, and discussion threads. Or, they are increasingly gaining options to communicate in real-time through chat or instant messaging, web conferencing, and audio and video response options, most of which are available within the course, or can be integrated within the course. So, essentially, face-to-face, ear-to-ear, and eye-to-eye communication is readily available to the online learners of today. Actually, there might be more ways to communicate with instructors and classmates online than there are in face-to-face classes. This could be classified as a nuisance to some, but for those who crave connection with instructors and peers in online classes, the communication options are very fulfilling.

Through email, text messaging, and discussion threads, students can contact instructors and classmates. Or they are increasingly gaining options for real-time communication through chat or instant messaging, online conferencing, and options for audio and video response, most of which are accessible or can be incorporated into the course within the course. So, literally, faceto-face, ear-to-ear, and eye-to-eye contact is easily accessible to today's online learners (Athena Kennedy, 2015).

\subsection{Trending Distance E- Learning Technologies}

Upgrading the e-learning experience begins with presenting the online learning resources and during the virtual school day, tech students and educators have access to them. Some of these technological tools are discussed here. 


\subsection{Zoom for Home - DTEN ME}

Zoom is a software program developed by Zoom Video Communications for video telephony. The free edition offers a video chat service that allows up to 100 devices at once with free accounts requiring meetings of three or more members being subject to a 40 -minute time limit. By subscribing to one of its plans, users have the option to upgrade, with the highest allowing up to 1,000 people simultaneously, with no time limit.

A new product category, Zoom for Home, developed with remote work and distance learning in mind, was recently announced by Zoom. DTEN ME, the first Zoom for Home product, is an outstanding distance learning all-in-one workstation. For immersive lessons, the 27 -inch 1080p LED touchscreen offers students plenty of digital workspace. Many laptops with very lacklustre microphones and webcams are normal.

The DTEN ME features three wide-angle cameras and an eight-microphone array built into the device that enhances audio and video during lessons.

\subsection{Tablet - Apple iPad}

Not all students will prefer the look and feel of a 2-in-1 device and some may appreciate a dedicated tablet. With up to 128GB of storage, the classic iPad is a great option and now supports the Apple Smart Keyboard for added versatility. The 10.2-inch Retina display offers plenty of digital workspace in a compact, lightweight handheld device. During more interactive assignments, these handy tools can help with digital collaboration and some students may choose to take notes on the tablet.

\subsection{Best 2-in-1 laptop - Microsoft Surface Pro 7}

A great choice for distance learning is the ever-popular 2-in-1 laptop design. These models allow learners to leverage a conventional screen-and-keyboard style interface while offering a standalone tablet's flexibility and functionality. With this in mind, for those so inclined, the Microsoft Surface Pro 7 is a solid 2-in-1 model.

For optimum performance during the digital school day, the Surface Pro features a 10th Gen Intel Core i7 processor and up to $1 \mathrm{~TB}$ of ram. For interactive lessons, front- and rear-facing cameras (1080p) enable visual collaboration. The Surface Pro 7 will last more than 10 hours on a single charge, the manufacturer estimates.

\subsection{HD Video Webcam}

Not all computers come with high-quality webcams and this hardware is completely missing in certain more affordable models. For those looking to develop their e-learning experience, a simple webcam is also a great choice. Logitech C270 3MP Webcam is an example that provides HD widescreen video and also corrects lighting for crisper video automatically. A universal clip comes with the $\mathrm{C} 2703 \mathrm{MP}$ and is conveniently connected to a wide variety of monitors and laptop screens.

\subsection{Noise-cancellation headphones such as COWIN E7 PRO}

For some students and teachers, studying at home can be distracting. For individuals who want to block outside distractions and tune in for the lesson at hand, headphones are a great choice. 
This COWIN model features technology for noise-cancelling to further reduce background noise during lessons. The manufacturer claims that this model is able to operate on a single charge for 30 hours, which is more than adequate for several school days.

\subsection{DOSS SoundBox Touch Portable Wireless Bluetooth Speaker}

Not all machines have been equipped with onboard top-notch speakers. These factory components will pop and crackle at higher volumes, significantly reducing the quality of sound. Clean, crisp audio is crucial in an online lesson. For those looking to turn up the volume and dial in for a lecture, a Bluetooth speaker is a great choice. Students may also play their favourite research playlists using the speaker during independent learning.

\subsection{External microphone such as Shure MV5}

Another simple way to give your virtual partnership a boost is a dedicated external microphone. The Shure MV5 is an outstanding compact model with numerous pre-set modes (instrumental, flat, vocals) to provide a host of acoustic settings with superior audio quality. The microphone also detaches from the small mount for a more low-profile fit on a workstation as an added bonus.

\subsection{USB Data Hub Splitter}

Many learners, sometimes at the same time, need to leverage multiple devices. To assist with external recharges, many newer laptops have few (if any) USB ports. In addition, running both of these devices off the laptop will drain its battery halfway through the school day quickly. A dedicated external USB charging hub, for this purpose and others is a perfect way to keep all your devices fully charged without covering your laptop under a mountain of cables and dongles.

\subsection{Learning Management System (LMS)}

A learning management system (LMS) is a software application for the administration, documentation, tracking, reporting, automation and delivery of educational courses, training programs, or learning and development programs (Ellis, 2009).

The idea of the learning management system originated directly from e-Learning. While the first LMS emerged in the higher education sector, most of the LMSs are now focused on the corporate market. Learning Management Systems make up the largest segment of the market for learning systems. The LMS's first appearance was in the late 1990s (Davis, 2009).

The LMS market is expected to be worth over $\$ 15.72$ billion in 2021 . The highest proportion of revenue contribution is expected to be generated in North America. $41.7 \%$ of global Fortune 500 companies now use some form of educational technology to instruct employees during formal learning hours. Roughly half of all college classes will be eLearning-based. It is more than obvious that eLearning has revolutionized and changed the way we look at knowledge and skill acquisition. Thereby, there is an increasing demand for Learning Management Systems to systematically implement and manage eLearning. With 1000+ LMS vendors and too many LMS features to choose from, we can definitely say that Learning Management Systems are here to stay. 


\subsection{Why Consider LMS?}

Many global secondary and higher education institutions have been experimenting with Learning Management Systems (LMS) in recent years, which have seen some substantial improvements in their structure, functionality, and effectiveness. This technology helps schools develop, implement, manage, distribute, and manage all of the activities associated with online education.

This technology can make the classroom experience more efficient, easier, more personalized, and interactive when introduced.

\subsection{Features of LMS}

Certification: When students complete a course or do well in the test, they are given a certificate that will increase their morale to learn more.

Customisation: Customizing the application with your institute's name, logo and even primary colours according to your needs and also white-labelling the platform.

Mobile learning: Most providers offer mobile apps that allow students to access their learning content at anytime and anywhere.

Multi-Lingual Support: For organizations with students in certain parts of the world, this function must be considered in order to avoid the language barrier.

Real-time reporting and analytics: Daily, weekly, monthly and custom reports of the learners based on their performance and progress can be generated. The activity status can also be viewed by the administrators.

API and third-party integrations: Some vendors allow their LMS platform to integrate with third-party applications like HRMS, Adobe Flash, Gmail, mobile applications etc.

Social Learning: Group chats allow learners to share and interact with their peers with learning materials and knowledge through options such as live chat. Teamwork and casual contact are also facilitated by this.

Blended learning: For better engagement of the learners, some platform allows traditional classroom training and also modern ways of teaching like Webinars, podcasts, ILT, use of multimedia, SCORM courses etc.

\subsection{Cloud-Based LMS List Ranking}

1. Docebo

2. Adobe Captivate Prime

3. TalentLMS

4. SAP Litmos LMS

5. LearnUpon LMS

6. Inquisiq LMS

7. LearningPool 
8. Mindflash

9. Absorb LMS

10. iSpring Learn

11. Looop

12. LearnAmp

13. GnosisConnect

14. Coassemble

15. Effectus LMS

16. Tovuti

17. Growth Engineering's Academy LMS

18. Skillcast LMS

19. CoreAchieve

\subsection{Open Source LMS List Ranking}

1. Moodle

2. Chamilo

3. Open edX

4. Totara Learn

5. Canvas

\subsection{Conclusion}

COVID-19 has exposed a much larger audience to distance learning. As a consequence, to bring teachers and students on board with the new technologies as soon as possible, schools had to develop or fast-track online education plans. There is already a collection of software applications and frameworks in place to promote online education, but more changes are needed to make it easier to learn and use these resources.

Although e-learning has been dramatically enhanced by online technologies and the growing EdTech industry, only those that have access to broadband internet service and a computer have benefited. The COVID-19 shutdown has illustrated and intensified the current worldwide digital divide. Half of all students deprived of in-person lessons due to the pandemic do not have internet access, according to UNESCO. In their households, over 40 percent are without internet access.

This problem has to be addressed to have a seamless and fair distance e-learning atmosphere where the technologies mentioned in this work will be fully enjoyed by all students. 


\subsection{References}

Athena Kennedy, P. (2015, July 17). New Technology Takes the Distance Out of Distance Learning. $\quad$ Retrieved November 24, 2020, from http://blog.online.colostate.edu/blog/online-teaching/new-technology-takes-the-distanceout-of-distance-learning/

Bingham, J., Davis, T., \& Moore, C. (n.d.). Emerging Technologies in Distance Learning. $\begin{array}{llll}\text { Retrieved November } & 24, & \text { 2020, }\end{array}$ http://horizon.unc.edu/projects/issues/papers/Distance_Learning.html

Cartwright, G. P. (1994, July/August). Distance Learning: A different time, a different place. Change, $(26,4)$ [online serial].

Davis, B., Carmean, C., \& Wagner, E. (2009). "The Evolution of the LMS : From Management to Learning". The ELearning Guild Research. 24

Ellis, Ryann K. (2009), Field Guide to Learning Management, ASTD Learning Circuits, archived from the original on 24 August 2014, retrieved 5 July 2012

United States Distance Learning Association (USDLA), (1996, January 26). Distance Learning Fact Sheet [WWW document]. 